\title{
Non-ulcer dyspepsia and peptic ulcer: the distribution in a population and their relation to risk factors
}

The Sørreisa gastro-intestinal disorder study. B Bernersen, R Johnsen, B Straume

\begin{abstract}
Background-The aetiology of non-ulcer dyspepsia and a possible connection to peptic ulcer disease is debated. This paper discusses this problem in a population based study.

Aims-The relation between non-ulcer dyspepsia and peptic ulcer disease was explored by the distribution in the general population and their associations to demographic, lifestyle, and psychological factors.

Methods-All inhabitants of a community aged 20-69 years received a questionnaire concerning abdominal complaints, health, lifestyle, diet, and social conditions. Reports on peptic ulcer were verified with medical records. Dyspeptic subjects and matched healthy, non-dyspeptic controls were endoscoped in a blinded procedure. Subjects-Of 2027 persons invited, 1802 $(88.9 \%)$ returned the questionnaire from which dyspeptic subjects and controls were identified. Of 782 subjects invited to endoscopy, 309 dyspeptic and 310 control subjects $(79 \cdot 2 \%)$, participated.
\end{abstract}

Results-Men reported dyspepsia (30.4\%) and peptic ulcer $(8 \cdot 7 \%)$ more often than women $(24 \cdot 1 \%$ and $5 \cdot 2 \%$, respectively). Non-ulcer dyspepsia was frequent (between 10.6\% and 17.2\%) in both sexes and age groups up to 60 years, with a lower frequency in both men and women above this age (3.0\% and 6.8\%). Non-ulcer dyspepsia was associated with having a family history of dyspepsia and of peptic ulcer and the use of tranquillisers. Nearly one third of dyspeptic persons above the age of 40 years had peptic ulcer, but peptic ulcer prevalence was low under this age. Peptic ulcer was associated with a family history of peptic ulcer, smoking, and daily life stress, and also with poor living conditions during childhood, frequent recurrence of herpes labialis, conditions that were associated with Helicobacter pylori infection.

Conclusions-Non-ulcer dyspepsia and peptic ulcer have different patterns of relations to lifestyle, social, and psychological factors. The results perhaps support the hypothesis of peptic ulcer being an infectious disease in contrast with nonulcer dyspepsia.

(Gut 1996; 38: 822-825)

Keywords: dyspepsia, peptic ulcer, population study, Helicobacter pylori, lifestyle.
It is usual that about one third of dyspeptic patients claim to have peptic ulcer disease. The frequency of 'unexplained' dyspepsia depends, however, on the selection of patients. While Gregory et al found that only three of 102 dyspeptic patients in general practice developed a peptic ulcer, ${ }^{1}$ Kragh found this in $40 \%$ of hospitalised patients. ${ }^{2}$

One study on peptic ulcer disease and nonulcer dyspepsia in a large population ${ }^{3}$ has shown that these conditions had substantially different relations to psychological, social, lifestyle, and dietary variables. Peptic ulcer was strongly associated with age, a family history of peptic ulcer, body mass index, and smoking, whereas non-ulcer dyspepsia was associated with psychological factors and social conditions. In this large population study, however, the diagnoses were not verified. A population based case control study of risk factors in prepyloric and duodenal ulcer patients and controls gave no support to the concept that peptic ulcer disease is a disorder related to psychological stress. ${ }^{4}$

Are peptic ulcer disease and non-ulcer dyspepsia, despite similar symptoms, aetiologically and pathogenetically different conditions? To elucidate the relation between non-ulcer dyspepsia and peptic ulcer disease, we have studied their distribution in a general population and their associations to possible aetiological factors.

\section{Methods}

From March to May 1987 all inhabitants of the municipality of Sørreisa in northern Norway aged 20 to 69 years, 2027 men and women, received a postal questionnaire with questions concerning abdominal complaints, health, lifestyle, diet, and social conditions. Of 2027 persons invited, $1802(88.9 \%)$ returned the questionnaire. The inhabitants of this municipality have all their medical contacts with one of the two family physicians at the one and only local health service centre, and their hospital services from the one and only regional hospital. All reports of a previously diagnosed peptic ulcer, were verified by searching individual medical records, which were easily identified in the local health service centre or at the regional hospital.

All subjects giving affirming answers to the first two or the last of the following questions were considered dyspeptic patients: 'Have you ever had abdominal pain of at least two weeks' duration?'; 'If yes, was the pain located to the upper abdomen?' and 'Have you ever had 
TABLE I Prevalences (\%) of reported epigastric pain and heartburn (dyspepsia), diagnosed non-ulcer dyspepsia, and verified peptic ulcer according to 10 year age groups and sex. Sorreisa 1987

\begin{tabular}{|c|c|c|c|c|c|c|c|c|}
\hline \multirow[b]{2}{*}{ Age group } & \multicolumn{2}{|c|}{ Number } & \multicolumn{2}{|c|}{$\begin{array}{l}\text { Dyspepsia } \\
(n=409)\end{array}$} & \multicolumn{2}{|c|}{$\begin{array}{l}\text { Non-ulcer dyspepsia } \\
(n=233)\end{array}$} & \multicolumn{2}{|c|}{$\begin{array}{l}\text { Peptic ulcer } \\
(n=126)\end{array}$} \\
\hline & $M$ & $F$ & $M$ & $F$ & $M$ & $F$ & $M$ & $F$ \\
\hline $\begin{array}{l}20-29 \\
30-39 \\
40-49 \\
50-59 \\
60-69\end{array}$ & $\begin{array}{l}235 \\
200 \\
203 \\
133 \\
134\end{array}$ & $\begin{array}{l}195 \\
222 \\
189 \\
129 \\
162\end{array}$ & $\begin{array}{l}20 \cdot 4 \\
29 \cdot 0 \\
40.9 \\
33.8 \\
31.3\end{array}$ & $\begin{array}{l}19 \cdot 5 \\
27 \cdot 9 \\
25 \cdot 4 \\
24 \cdot 8 \\
22 \cdot 8\end{array}$ & $\begin{array}{r}10 \cdot 6 \\
15 \cdot 0 \\
17 \cdot 2 \\
13.5 \\
3.0\end{array}$ & $\begin{array}{r}13.3 \\
15.3 \\
15.9 \\
15.5 \\
6.8\end{array}$ & $\begin{array}{r}3 \cdot 0 \\
4 \cdot 0 \\
14 \cdot 8 \\
12 \cdot 8 \\
12 \cdot 7\end{array}$ & $\begin{array}{r}1 \cdot 0 \\
4 \cdot 1 \\
4 \cdot 2 \\
10 \cdot 9 \\
8 \cdot 6\end{array}$ \\
\hline Total & 905 & 897 & $30 \cdot 4$ & $24 \cdot 1$ & $12 \cdot 4$ & $13 \cdot 5$ & $8 \cdot 7$ & $5 \cdot 2$ \\
\hline
\end{tabular}

heartburn or acid regurgitation almost daily during at least one week?'.

Of 495 dyspeptic persons, 89 subjects reporting a prior history of peptic ulcer, 15 subjects reporting gall stones or kidney stones, and 33 reporting coronary heart disease, were all excluded. The remaining 358 persons were offered an endoscopy free of charge but without any reward. Healthy, nondyspeptic controls matched for sex and age within the same 10 year age group, were randomly selected and offered an endoscopy as well. The controls were selected from the questionnaire survey, as they reported that they never had experienced abdominal pain at any location or heartburn or acid regurgitation and that they never had consulted their general practitioner with dyspepsia. Of 782 subjects invited to endoscopy, $619(79 \cdot 2 \%)$ attended, of whom 309 were dyspeptic subjects and 310 controls. All subjects were endoscoped within one month after returning the questionnaire. After completing the verification procedure searching all local medical records for confirmation of a previous peptic ulcer and after endoscoping the 619 persons, 409 persons, of the initial 495 persons, reporting dyspepsia were without a previous or present peptic ulcer. A detailed description of the methods has been published elsewhere. ${ }^{5}$ The study was approved by the Regional Committee for Medical Research Ethics.

\section{Endoscopy study}

All endoscopies were performed by one of the authors (BB), who is a trained endoscopist. The endoscopist was masked to whether he examined a dyspeptic or a non-dyspeptic person. A gastric or duodenal ulcer was diagnosed if an ulceration greater than $0.5 \mathrm{~cm}$ was seen proximally or distally to the pylorus, respectively. Deformity of the duodenal bulb was considered to be present when flattening, scars, stenosis, or narrowing of the bulb was seen. Endoscopic duodenitis was diagnosed according to the criteria of Venables. ${ }^{6}$

Biopsy specimens for histological diagnosis were taken from all lesions. Stomach biopsy specimens for Helicobacter pylori cultures, were placed in $0.5 \mathrm{ml}$ of glucose/saline solution ( $25 \%$ glucose in $0.9 \%$ saline solution), ground, and dispersed on blood agar and on brain-heart infusion agar containing horse $(5 \% \mathrm{v} / \mathrm{v})$ blood within five minutes after endoscopy. ${ }^{7}$
Definition of groups for analysis

Dyspeptic group - All persons with dyspepsia as defined above, but without a present or previous peptic ulcer.

Non-ulcer dyspepsia - All dyspeptic subjects attending the endoscopic study without a peptic ulcer, deformity of the duodenal bulb or endoscopic duodenitis of the duodenal bulb.

Peptic ulcer - All persons with peptic ulcer, verified with any of the medical records and all persons having a peptic ulcer or an ulcer scar (deformed duodenal bulb) at the endoscopy.

Reference population - In the logistic regression analysis of dyspepsia, non-ulcer dyspepsia and peptic ulcer, the reference population comprised subjects without any of the mentioned conditions.

\section{Regression analyses}

The following independent variables were explored and finally assessed in a logistic regression: age; sex; daily smoking (yes/no); number of cigarettes smoked daily; previous smoking (yes/no); coffee consumption (none or less than 1 cup a day, 1-5 cups, and 6 cups or more a day); beer, wine and liquor consumption (graded 0-2); nourishment as baby (mother's milk or not); regularity of meals; excessive use of spices, ketchup or mustard, use of some specific drugs (aspirin, nonsteroidal anti-inflammatory drugs, sleeping pills and tranquillisers), shift work (all yes/no); social stress (four categories, never to all the time); physical activity at leisure time (graded 1-4: sedentary, moderate, active, and hard training); living conditions during childhood (four categories, from very difficult to very good), and dyspepsia or peptic ulcer, or both, in the family (first degree relatives); bothered by herpes labialis (four categories, never to frequent); reporting complaints as frequent headache, unspecific vertigo, palpitations and insomnia, where reporting more or less than two of these symptoms, respectively, were graded as yes/no.

\section{Statistical methods}

Age trends were tested by Mantel-Haenszel $\chi^{2}$ test. Logistic regression and adjustment for age and sex distribution by analysis of covariance were made in the SPSSX statistical program.

\section{Results}

Table I shows the prevalences of reported dyspepsia, non-ulcer dyspepsia, and peptic ulcer. Of the 309 persons with dyspepsia endoscoped, 31 had a peptic ulcer or a deformed duodenal bulb at the present time and $45 \mathrm{had}$ an endoscopic duodenitis, leaving 233 persons with non-ulcer dyspepsia.

There were no significant differences in frequency of dyspepsia between the two sexes when stratified for age, but there was a slightly increasing trend with age in the frequency of dyspepsia in men $(p=0.003)$. The prevalence of non-ulcer dyspepsia did not differ between the sexes and seemed stable throughout the 
age span, only showing a pronounced decrease in the age group above 60 years. Peptic ulcer had a significant sex difference with more diagnosed peptic ulcers in men $(p=0.002)$ and an increasing prevalence with age for both sexes $(p<0.0001)$ with a pronounced increase in men aged over 40 years and women aged over 50 years.

Table II shows the results of the regression analysis. A corresponding analysis of dyspepsia excluding persons reporting irritable bowel symptoms according to Manning's criteria, ${ }^{8}$ gave mainly the same results as presented for dyspepsia. The non-ulcer dyspepsia group, consisting of the subjects with dyspepsia in the endoscopy population when excluding organic pathological endoscopic findings, had chiefly the same relations as the dyspepsia group, but in addition showed a significant association with use of tranquillisers. The analysis of nonulcer dyspepsia contrasted with the matched controls gave the same relations (with a somewhat lower strength).

Finally, in persons with peptic ulcer disease, there were significant contributions from age, sex, family history of peptic ulcer, smoking, previous smoking, tea drinking, frequent recurrences of herpes labialis, breast fed as a baby, poor living conditions during childhood, and the feeling of lack of time.

In an analysis of the endoscoped persons, $H$ pylori infection was found in $49.6 \%$ of subjects having frequent recurrences of herpes labialis, while subjects never or seldom having this condition were infected in $39.7 \%$ $(p=0.04)$. Subjects having poor living conditions during their childhood were infected with $H$ pylori in $49.6 \%$, while subjects having good or fair living conditions during their childhood had this infection in $37.5 \%(p=0.003)$.

\section{Discussion}

Dyspepsia is a common disorder, even when symptoms are restricted to upper abdominal pain and heartburn or acid regurgitation of at least two weeks' duration as in this study. We found that men were more likely to be afflicted with dyspepsia, with a small increase with age, unlike women. Non-ulcer dyspepsia occurred with a similar frequency in both sexes up to 60 years, but was less common in older people of both sexes. Peptic ulcer was seldom found up to the age of 40 years in men and 50 years in women, but in older dyspeptic patients nearly one third had a peptic ulcer.

Dyspepsia has been defined and classified in various ways, ${ }^{9-11}$ but in this study the definition includes the most commonly accepted symptoms with a low grade of selection on severity and duration. In our definition of nonulcer dyspepsia, we have chosen to exclude both peptic ulcer, ulcer scars (deformity), and endoscopic duodenitis of the duodenal bulb. ${ }^{12}$

Our investigation shows that relations to background factors were quite similar for dyspepsia and non-ulcer dyspepsia, the only difference was that patients with non-ulcer dyspepsia, were treated, for example with reduction of coffee drinking and use of tranquillisers. In epidemiological studies there are few reasons to differentiate between dyspepsia and non-ulcer dyspepsia.

Non-ulcer dyspepsia was associated with a family history of peptic ulcer and also with a family history of dyspepsia. To our knowledge, there are no theories of inheritance of dyspepsia, but dyspeptic symptoms may be inherited by learning habits and how to report them. ${ }^{13}$ Our finding of a relation to previous smoking in dyspeptic subjects similar to the association between peptic ulcer and tea drinking, may be seen as a result of changed habits related to the disease. ${ }^{14}$ We know of no previous reports on associations between tea drinking and peptic ulcer and this finding may be a spurious one or show changed habits among peptic ulcer patients because of medical counselling. Tea drinkers controlled for earlier coffee drinking showed that $38 \%$ of dyspeptic subjects and $21 \%$ of non-dyspeptic subjects had stopped coffee drinking.

Peptic ulcer has in this study a quite different pattern of relations, firstly to age and sex, but also to well known factors as smoking and a family history of peptic ulcer. For peptic ulcer this last relation may fit in with theories of inheritance, ${ }^{15}$ but also with family clustering of $H$ pylori. ${ }^{16}$ The relations to frequent recurrences of herpes labialis may indicate a connection to infectious diseases. We found an association between frequent herpes labialis recurrences and $H$ pylori infection. Duodenal ulcer has earlier been connected to herpes virus

TABLE II Odds ratio (OR) of the independent variables in a logistic regression analysis among 1802 men and women with dyspepsia $(n=409)$, non-ulcer dyspepsia $(n=233)$, and peptic ulcer $(n=126)$ in contrast with the reference population $(n=1267)$. Sorreisa 1987

\begin{tabular}{|c|c|c|c|c|c|c|}
\hline \multirow[b]{2}{*}{ Independent variable } & \multicolumn{2}{|c|}{$\begin{array}{l}\text { Dyspepsia } \\
(n=1676)\end{array}$} & \multicolumn{2}{|c|}{$\begin{array}{l}\text { Non-ulcer dyspepsia } \\
(n=1500)\end{array}$} & \multicolumn{2}{|c|}{$\begin{array}{l}\text { Peptic ulcer } \\
(n=1393)\end{array}$} \\
\hline & $O R$ & $C I^{\star}$ & $O R$ & $C I^{\star}$ & $O R$ & $C I^{\star}$ \\
\hline $\begin{array}{l}10 \text { Year age group } \\
\text { Sex (female=0, male }=1 \text { ) } \\
\text { Family history of dyspepsia (no/yes) } \\
\text { Peptic ulcer in the family (no/yes) } \\
\text { Smoking (no/yes) } \\
\text { Previous smoking (no/yes) } \\
\text { Tea drinking (no/yes) } \\
\text { Frequent herpes labialis (no/yes) } \\
\text { Breast feeding as baby (no/yes) } \\
\text { Frequent complaints (no/yes) } \\
\text { Use of tranquillisers (no/yes) } \\
\text { Feeling of lack of time (no/yes) } \\
\text { Poor living conditions during childhood (no/yes) }\end{array}$ & $\begin{array}{l}1 \cdot 02 \\
1.53 \\
2 \cdot 21 \\
1 \cdot 83 \\
1 \cdot 69 \\
1.98 \\
1 \cdot 15 \\
1 \cdot 40 \\
0.97 \\
2 \cdot 28 \\
1.50 \\
1 \cdot 06 \\
1 \cdot 15\end{array}$ & $\begin{array}{l}0.93 \text { to } 1.11 \\
1.19 \text { to } 1.96 \\
1.71 \text { to } 2.84 \\
1.41 \text { to } 2.37 \\
1.27 \text { to } 2.26 \\
1.43 \text { to } 2.73 \\
0.89 \text { to } 1.49 \\
1.05 \text { to } 1.85 \\
0.77 \text { to } 1.23 \\
1.69 \text { to } 3.09 \\
0.83 \text { to } 2.70 \\
0.78 \text { to } 1.43 \\
0.89 \text { to } 1.49\end{array}$ & $\begin{array}{l}0 \cdot 90 \\
0 \cdot 85 \\
2 \cdot 20 \\
1 \cdot 87 \\
1.46 \\
1 \cdot 58 \\
1 \cdot 16 \\
1 \cdot 27 \\
1 \cdot 29 \\
1 \cdot 68 \\
2 \cdot 07 \\
1 \cdot 25 \\
1 \cdot 22\end{array}$ & $\begin{array}{l}0.80 \text { to } 1.01 \\
0.63 \text { to } 1.15 \\
1.62 \text { to } 2.98 \\
1.36 \text { to } 2.58 \\
1.03 \text { to } 2.06 \\
1.06 \text { to } 2.34 \\
0.85 \text { to } 1.60 \\
0.90 \text { to } 1.81 \\
0.96 \text { to } 1.74 \\
1.14 \text { to } 2.46 \\
1.07 \text { to } 4.01 \\
0.88 \text { to } 1.78 \\
0.89 \text { to } 1.67\end{array}$ & $\begin{array}{l}1 \cdot 50 \\
1.90 \\
1 \cdot 54 \\
2 \cdot 50 \\
3 \cdot 53 \\
2 \cdot 08 \\
2 \cdot 41 \\
2 \cdot 13 \\
1.53 \\
1 \cdot 12 \\
0 \cdot 84 \\
1 \cdot 67 \\
1 \cdot 88\end{array}$ & $\begin{array}{l}1.28 \text { to } 1.76 \\
1.24 \text { to } 2.90 \\
0.94 \text { to } 2.40 \\
1.65 \text { to } 3.77 \\
2.08 \text { to } 5.98 \\
1.16 \text { to } 3.73 \\
1.59 \text { to } 3.67 \\
1.36 \text { to } 3.35 \\
1.01 \text { to } 2.32 \\
0.65 \text { to } 1.93 \\
0.32 \text { to } 2.20 \\
1.03 \text { to } 2.69 \\
1.25 \text { to } 2.82\end{array}$ \\
\hline
\end{tabular}

${ }^{\star} \mathrm{CI}=95 \%$ confidence intervals. 
infection and a theory proposing that duodenal ulcer could be of herpetic origin. ${ }^{1718} \mathrm{We}$ did not expect that being breast fed as baby would be associated with peptic ulcer. We found no relation between $H$ pylori infection and breast feeding as baby in this study and to our knowledge no data connecting these conditions exist. The relation is weak, and this finding should be interpreted with caution. Poor living conditions during childhood have been connected with low resistance against other diseases, ${ }^{19}$ but may also be connected with early infection of $H$ pylori. ${ }^{20}$ In our endoscopy group subjects with poor living conditions during their childhood had $H$ pylori infection significantly more often than those better off during their childhood. It may be hypothesised from these data that several putative risk factors for peptic ulcer are spurious and express an association with infective agents as $H$ pylori.

Regardless of the different pattern of relations to background factors between peptic ulcer and dyspepsia, the clinician will always ask when dyspepsia represents peptic ulcer or not. It would be financially worthwhile to carry out an endoscopy or a breath test diagnosing $H$ pylori infection. In our population study, the $H$ pylori status was obtained in all persons who had an endoscopy, dyspeptic as well as non-dyspeptic controls. ${ }^{7}$ From these data it is obvious that a positive $H$ pylori diagnosis could not tell us whether a dyspeptic person has a peptic ulcer or not. The question is whether or not the non-ulcerous mucosa will help the practitioner to decide what advice and what treatment to give. At least, the low occurrence of peptic ulcer among young people support a reluctant attitude towards endoscopy of young dyspeptic patients.

The results in this study may be questioned because of the comparatively small numbers for all groups studied. The cross sectional design does not allow us to make conclusive inferences on causality. Furthermore, we do not have data on the $H$ pylori occurrence in our total study group, only in the 619 subjects endoscoped. These disadvantages may to some extent be compensated by our comprehensive investigations to verify reported ulcers as most studies on peptic ulcer in studies with larger numbers are burdened with diagnostic problems. ${ }^{21}$ The 'blinding' of the endoscopy of all dyspeptic subjects and controls will also reduce the possibility of biased findings.

We conclude that non-ulcer dyspepsia and peptic ulcer have different patterns of relations to lifestyle, social, and psychological factors. The results of this study seem, with some reservations, to support the hypothesis of peptic ulcer being an infectious disease in contrast with non-ulcer dyspepsia.

1 Gregory DW, Davies GT, Evans KT, Rhodes J. Natural history of patients with X-ray-negative dyspepsia in general practice. $B M \mathcal{F}$ 1972; 4: 519-20.

2 Kragh E, Pseudo-ulcer and true peptic ulcer. A clinical, radiographic and statistical follow-up study. Acta Med Scand 1965; 178: 713-28.3.

3 Johnsen R, Straume B, Førde OH. Peptic ulcer and nonulcer dyspepsia - a disease and a disorder. Scand $\mathcal{f}$ Prim Health Care 1988; 6: 239-43.

4 Adami HO, Bergström R, Nyrén O, Forhaug K, Gustavsson $S$, Lööf $L$, et al. Is duodenal ulcer really a psychosomatic disease? A population-based case-control study. Scand $\mathcal{F}$ Gastroenterol 1987; 22: 889-96.

5 Bernersen B, Johnsen R, Straume B, Burhol PG, Jenssen TG, Stakkevold PA. Towards a true prevalence of peptic ulcer: the Sørreisa gastrointestinal disorder study. Gut 1990; 31: 989-92.

6 Venables CW. Duodenitis. Scand f Gastroenterol 1985; 20 (suppl 109): 91-7.

7 Bernersen B, Johnsen R, Bostad L, Straume B, Sommer AI, Burhol PG. Is Helicobacter pylori the cause of dyspepsia? BMY 1992; 304: 1276-9.

8 Manning AP, Thompson WG, Heaton KW, Morris AF. Towards positive diagnosis of irritable bowel. BMF 1978; 2: $653-4$

9 Heatley RV, Rathbone BJ. Dyspepsia: a dilemma for doctors? Lancet 1987; ii: 779-82.

10 Colin-Jones DG. Management of dyspepsia: report of a working party. Lancet 1988; i: 576-9.

11 Talley NJ, Zinsmeister AR, Schleck CD, Melton III J. Dyspepsia and dyspepsia subgroups: a population-based study. Gastroenterology 1992; 102: 1259-68.

12 Greenslaw R, Sheahan DG, DeLuca V, Miller D, Myerson D, Myerson P. Gastroduodenitis: a broader concept of peptic ulcer disease. Dig Dis Sci 1980; 25: 660-72.

13 Whitehead WE, Winget C, Fedoravicius AS, Wooley S, Blackwell B. Learned illness behavior in patients with irritable bowel syndrome and peptic ulcer. Dig Dis $S c i$ 1982; 27: 202-8.

14 Jacobsen BK, Bjelke E, Kvåle G, Heuch I. Coffee drinking, mortality and cancer incidence: results from a Norwegian prospective study. I Natl Cancer Inst 1986; 76: 823-31.

15 Anonymous. Duodenal ulcer inheritance [Editorial]. Lancet 1979; i: $650-1$.

16 Oderda G, Vaira D, Holton J, Ainley C, Altare F, Boero M, et al. Helicobacter pylori in children with peptic ulcer and their families. Dig Dis Sci 1991; 36: 572-6.

17 Vestergaard BF, Rune SJ. Type-specific herpes simplex virus antibodies in patients with recurrent duodenal ulcer. Lancet 1980; i: 1273-5.

18 Anonymous. Viruses and duodenal ulcer [Editorial]. Lancet 1981; i: 705-6.

19 Forsdahl A. Are poor living conditions in childhood and adolescence an important risk factor for arteriosclerotic disease? Br f Prevent Soc Med 1977; 31: 91-5.

20 Mendall MA, Goggin PM, Molineaux N, Levy J, Toosy T, Strachan $\mathrm{D}$, et al. Childhood living conditions and Helicobacter pylori seropositivity in adult life. Lancet 1992; 339: 896-7.

21 Langman MJS. Changing patterns in the epidemiology of peptic ulcer. Clinics in Gastroenterology 1973; 2: 219-26. 